\title{
CATULO 64: UMA PROPOSTA DE TRADUÇÃO POÉTICA
}

\section{CATULLUS 64: A PROPOSAL OF POETIC TRANSLATION}

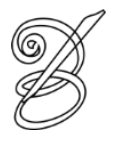

Flavia Fróes da Motta BUDANT*

Universidade da Região de Joinville

Joinville, Santa Catarina, Brasil

\begin{abstract}
Resumo: Esta tradução tem como objetivo recriar a composição métrica de um excerto do Catulo 64, um epílio do poeta latino Caio Valério Catulo, com a aplicação das normas da métrica clássica da poesia em português, atribuindo valor e tonicidade às sílabas e às palavras. Esse poema em particular é um epitalâmio, uma canção escrita para ser lida em cerimônias nupciais, cujos personagens principais são Peleu e Tétis. O texto selecionado retrata o abandono de Ariadne por Teseu, recontado por êcfrase, uma narrativa presente em objetos inanimados neste caso, um manto bordado com os momentos de agonia e amaldiçoamento da filha de Minos na praia de Naxos enquanto vê seu amante deixá-la, despreocupado, após a vitória sobre o Minotauro, irmão dela. O metro original latino é o hexâmetro dactílico, composto por seis pés dáctilos, com substituições, como a inclusão de espondeus. Aqui, em português, os versos seguiram uma lógica similar, e houve a tentativa de emular tanto o tom épico quanto a cadência musical do Catulo 64.
\end{abstract}

Palavras-chave: Hexâmetro dactílico em português. Catulo. Tradução poética. Poesia clássica. Métrica latina.

Abstract: This translation aims to recreate the metrical composure of an excerpt of the Catullus 64, an epyllion by the Latin poet Gaius Valerius Catullus, by ways of applying the rules of classical poetic meter in Portuguese and ascribing values and stress to syllables and words. This particular poem is an epithalamium, a song written to be read at a wedding ceremony, whose main characters are Peleus and Thetis. The extract chosen depicts the abandonment of Ariadne by Theseus, told through ecphrasis, a narrative presented on inanimate objects - in this case, a coverlet with the embroidery that recounts the agonising and vituperating of Minos'daughter on the shore of Naxos, as she sees her lover absent-mindedly leaving after the victory over the Minotaur, her brother. The original latin meter is the dactylic hexameter, composed by six dactylic feet, with replacements, as the inclusion of spondees. Here, in Portuguese, the verses followed a similar rationale, and it was made an effort to emulate both the epic tone and the musical cadence of the Catullus 64.

Keywords: Dactylic hexameter in portuguese. Catullus. Poetic translation. Classical poetry. Latin meter.

RECEBIDO EM: 21 de setembro de 2019

ACEITO EM: 25 de novembro de 2019

PUBLICADO EM: março 2020 


\section{Caio Valério Catulo, autor}

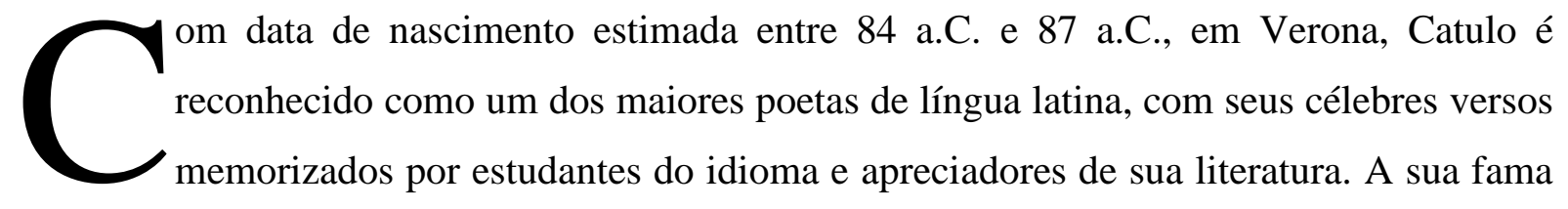

se deve tanto aos poemas de escárnio quanto aos de temática mais lírica, com variedade métrica que lhe confere a característica musicalidade dos carmina latinos. O poema 64, aqui traduzido, é classificado como um epílio, isto é, um poema épico de proporções menores cuja temática amorosa destoa dos feitos heroicos narrados em obras consagradas de mesmo metro, como os poemas homéricos e a Argonautica, de Apolônio, com que guarda estreita relação este carmen.

O poema é um epitalâmio, uma canção escrita para a noiva a caminho de sua câmara nupcial, com a narração das bodas de Peleu e Tétis, com pouco mais de 400 versos. Logo nos primeiros versos entramos em contato com o mito dos Argonautas, com a Argo surgindo entre as ondas e, assim, ocorrendo o encontro de uma das Nereides, Tétis, com o herói Teseu. O fragmento escolhido constitui parte da êcfrase do manto nupcial de Tétis, uma descrição detalhada de uma obra de arte com a vivacidade de um cenário, e relata a história de amor de 120 Teseu e Ariadne. O poema narra a vitória de Teseu, que, ajudado por Ariadne, irmã do Minotauro, consegue derrota-lo e livrar Atenas dos sacrifícios instituídos para aplaca-lo. Ariadne, que pretere a família para auxiliar o hóspede por quem se apaixona, é desprezada por Teseu e a cena de seu abandono na praia, invocando que as Eumênides e os deuses façam justiça à traição, já foi associada ao topos recorrente da deslealdade de Lésbia, figura feminina central nos poemas líricos de Catulo.

O Catulo 64 foi escrito em hexâmetros dactílicos, metro de escolha para épicos de língua grega e latina, e a tradução busca emular o mesmo sistema de pés e rítmica, com alternância entre o pé dátilo e o espondeu, tal qual no original, para criar dinamicidade e, ao mesmo tempo, uma cadência constante inteligível. A edição utilizada para o texto em latim é a anotada e editada por R. A. B. Mynors, da Scriptorum Classicorum Bibliotheca Oxoniensis, publicada pela Oxford University Press (ver Referências). 


\section{CAtulo 64}

"Pérfido, assim, a mim retirada das aras paternas,

pérfido, em praia deserta, Teseu, me abandonas agora?

Foges assim esquecido e a vontade dos deuses rejeita,

Levas perjúrios malditos, imêmore, à tua morada?

Coisa alguma alterar pode o plano cruel de tua mente?

Não restou nada em teu peito algoz de clemência comigo

Para sentir compaixão e abrandar a dor que me aflige?

Antes não me concedeste promessas em voz abrandada,

Nem me mandaste esperanças suster, ai de mim, tão aflita e

Sim me dera às núpcias e aos himeneus desejados.

Tudo, tudo lançado aos ventos e dissipado nos ares.

Que nunca creia mulher alguma em homens com juras.

Não esperem votos fiéis das palavras que falam;

Pois enquanto desejam suas almas e anseiam ter algo,

Nada hesitam em jurar, e não poupam promessas vazias;

Mas quando está em suas mentes saciada a libido ardente,

Não se recordam dos ditos e não lhes preocupa a perjúria.

Eu, quando tu em meio a um turbilhão rodeavas,

Te arrebatei e o irmão preferi relegar com desprezo

A lhe faltar, traidor, em tempo tão frágil e extremo.

Aos animais serei dada, em troca, como alimento,

Dilacerada e, já morta, a terra não há de cobrir-me.

Quem te criou, nas rochas desertas, leoa selvagem?

Qual foi o mar que expulsou-te das brancas espumas salinas?

Arruinou-te qual Sirtes, qual Cila feroz, ou Caríbdis?

$\mathrm{Tu}$, que pagaste tal preço por uma vida tão doce.

Se tu não estavas de fato em acordo com as nossas núpcias

Pois receavas as ordens ferozes de um pai tão severo,

Tu pelo menos, podias à casa tua levar-me

Para que eu fosse tua escrava e feliz te servisse,

E te amimasse, serena, lavando teus pés na corrente 
Água e a púrpura veste estendesse em teu leito com zelo.

Mas por que eu, sem sentido, à brisa néscia me queixo,

Desatinada de dor, a ela, que, sem qualquer alma,

Não pode ouvir minha voz ou ecoar-me nada em resposta?

Ele, porém, já em meio às ondas se encontra, cercado,

Não me aparece sequer um mortal nessas algas desertas.

Dessa maneira me insulta, cruel em excesso, a Fortuna,

Em momentos finais e ouvidos não dá-me aos lamentos.

Júpiter onipotente, quem dera que em tempos primeiros

Não atingissem a costa cnóssia as naus de Cecrópia,

Nem que portando infaustos tributos ao touro indomado o

Pérfido nauta com suas amarras ali aportasse,

Nem que, cruel, e ocultando seus atos em doces maneiras

Em nossa própria morada tal hóspede fosse acolhido.

Pois onde devo ir agora? E a qual esperança me prendo?

122 Corro aos montes do Ida? Mas se um abismo nos parte,

Vasto, e divide-nos tão truculento o plano dos mares.

Ou buscarei auxílio paterno? Ele, que eu própria

Abandonei, espargido em sangue fraterno, por outro?

Devo então consolar-me no amor de um esposo que foge,

Com os seus remos vergados, atravessando este abismo?

E além disso, esta praia é remota, sem qualquer casa,

Nem há caminhos no mar dentre o cerco visível das ondas.

Sem esperanças ou causas p'ra fuga, tudo emudece,

Tudo é deserto, todas as coisas erigem a ruína.

Mas os meus olhos a Morte não há de tornar embaçados,

Sem que eu implore aos deuses, traída, o justo castigo

E à hora final o amparo dos deuses me seja brindado.

Pois, então vós, castigantes, que as penas infligem aos homens,

Que no cabelo, Eumênides, portam serpentes, à fronte,

Que em si trazem, exalando, o furor do fundo do peito,

Vós para cá, vinde, aqui, e ouvi enfim as minhas queixas,

Queixas as quais, ai de mim!, de meu eu mais íntimo arranco 
Peço, sem meios, ardendo, e cega por louco delírio,

Pois que elas nascem, sinceras, no mais fundo sítio do peito,

Não permiti que essa minha aflição em vão desvaneça,

Mas qual Teseu teve em si de deixar-me sozinha na praia,

Deusas, assim a ele e aos seus levai a ruína."

\section{REFERÊNCIAS}

MYNORS, R. A. B. C. Valerii Catulli carmina. Oxford: Oxford University Press, 1989.

\footnotetext{
* Flavia Fróes da Motta BUDANT - Graduada em Letras, ênfase em Estudos Literários (2016) pela Universidade Federal do Paraná. Graduanda em Medicina pela Universidade da Região de Joinville. Joinville, Santa Catarina, Brasil.

Currículo acadêmico: http://lattes.cnpq.br/4131896645464041

ORCID: https://orcid.org/0000-0001-7836-2608

E-mail: flaviafmotta@gmail.com
} 